\title{
O ESVERDEAMENTO DOS TEXTOS CONSTITUCIONAIS BRASILEIRO E URUGUAIO: uma análise comparativa dos focos da tutela constitucional ambiental
}

\author{
THE GREENING OF BRAZILIAN AND URUGUAYAN CONSTITUTIONAL TEXTS: \\ a comparative analysis of the focuses of environmental constitutional protection
}

Recebimento em 13/03/2021

Luiz Guilherme Carvalho ${ }^{1}$

Aceito em 11/05/2021

\author{
João Paulo Rocha de Miranda ${ }^{2}$
}

\section{RESUMO}

A Constituição da República Federativa do Brasil de 1988, doravante chamada apenas de $\mathrm{CF} / 88$, é o primeiro texto constitucional brasileiro esverdeado, ao prever um capítulo próprio sobre meio ambiente. Essa inovação permite discussões sobre como foi a atuação do poder constituinte originário, os principais partidos atuantes e temas discutidos. Neste sentido, o presente estudo tem por objetivo analisar o Anteprojeto da Subcomissão de Saúde, Seguridade e Meio Ambiente formulada por Deputados Constituintes e suas emendas, com fulcro em verificar a atuação partidária e os temas ambientais mais debatid os no contexto de gênese da CF/88. Ademais, buscase comparar os focos da tutela ambiental nos textos constitucionais brasileiro e uruguaio. Tem-se por objeto de pesquisa o Anteprojeto, suas emendas e as cartas constitucionais do Brasil e Uruguai. A metodologia é de natureza qualiquantitativa, o método de abordagem é dedutivo e de procedimento histórico-comparativo, cujas técnicas são bibliográfica, documental e exploratória. Verificou-se que um dos assuntos mais abordados na elaboração do Anteprojeto pelos constituintes refere-se às atividades nucleares (14,5\%) e proteção ambiental e da saúde (11,59\%). Da comparação dos textos constitucionais brasileiro e uruguaio, percebe-se que, diferentemente do Brasil, o legislador constituinte uruguaio atribuiu, ao acesso à água, natureza de direito humano fundamental.

Palavras-chave: Água. Anteprojeto. Assembleia Nacional Constituinte. Meio ambiente. Partidos políticos.

\section{ABSTRACT}

The 1988 Constitution of the Federative Republic of Brazil, hereinafter referred to only as $\mathrm{CF} / 88$, is the first greenish Brazilian constitutional text, as it provides for its own chapter on the environment. This innovation allows discussions about how the original constituent power went, the main active parties and topics discussed. In this sense, the present study aims to analyze the preliminary draft of the Subcommittee on Health, Safety and Environment formulated by Constituent Deputies and their amendments, with a focus on verifying the partisan performance and the most debated environmental issues in the context of the genesis of CF / 88 . In addition, we seek to compare the focus of environmental protection in the Brazilian and Uruguayan

\footnotetext{
${ }^{1}$ Acadêmico de Direito da Universidade Federal de Mato Grosso, Campus Universitário do Araguaia (UFMT/CUA). Membro do Grupo de Pesquisa em Direitos Fundamentais na Fronteira, da Universidade Federal do Pampa (GPDIFF/UNIPAMPA).

${ }^{2}$ Professor Adjunto da Universidade Federal do Pampa (UNIPAMPA). Doutor em Direitos Humanos. Mestre em Direito Agroambiental. Líder do Grupo de Pesquisa em Direitos Fundamentais na Fronteira, da Universidade Federal do Pampa (GPDIFF/UNIPAMPA).
} 
constitutional texts. The object of research is the Draft, its amendments and the constitutional charters of Brazil and Uruguay. The methodology is of a qualitative and quantitative nature, the method of approach is deductive and of historical-comparative procedure, whose technique is bibliographic, documentary and exploratory. It was found that one of the subjects most addressed in the preparation of the Draft by the constituents refers to nuclear activities $(14.5 \%)$ and environmental and health protection $(11.59 \%)$. From the comparison of the Brazilian and Uruguayan constitutional texts, it is clear that, unlike Brazil, the Uruguayan constituent legislator attributed, to access to water, the nature of a fundamental human right.

Keywords: Water. Draft. National Constituent Assembly. Environment. Political parties.

\section{INTRODUÇÃO}

A Constituição Federal de 1988, formulada por uma Assembleia Nacional Constituinte (ANC) legitimamente constituída por representantes do povo, destinou um capítulo próprio para tratar da matéria ambiental em seu texto. Trata-se de uma inclusão normativa inovadora no contexto do constitucionalismo histórico brasileiro, ante a inexistência de tal reconhecimento em textos supremos anteriores, em um processo de esverdeamento constitucional, que traz nova perspectiva, sujeitando o crescimento econômico a uma forte preocupação socioambiental, avesso ao extrativismo exacerbado e de questionável racionalidade.

Considerando a ascensão do poder constituinte originário após longo período de ditadura militar contrário aos movimentos populares emergentes, faz-se importante compreender o contexto de elaboração das normas constitucionais ambientais, onde a atuação de ativistas ambientalistas foi salutar nesse processo, ainda que de forma diminuta.

Diante da atual realid ade normativa constitucional-ambiental do Brasil, questiona-se: como foi o processo legislativo do poder constituinte originário até o atual texto constitucional ambiental descrito no artigo 225? Quais os sujeitos que mais atuaram em prol da disposição normativa do meio ambiente no texto constitucional já que, à época, não se tinha nenhuma experiência de disposição ambiental em um texto constitucional brasileiro? É possível estabelecer um recorte sobre os temas mais debatidos no processo de constitucionalização da matéria ambiental em âmbito nacional? O que se depreende da análise comparada entre o texto constitucional brasileiro e a Constitución de La República Oriental Del Uruguay de 1967, foco dos mais recentes estudos do constitucionalismo latino-americano voltado a pensar o Direito Constitucional voltado para a proteção ecológica?

Neste sentido, a presente pesquisa busca responder a esses questionamentos, cujo objetivo precípuo é analisar comparativamente os focos que, os legisladores constituintes originários, mas também derivados, deram à tutela ambiental, no Brasil e no Uruguai. Para tanto, é examinado desde o Anteprojeto da Subcomissão de Saúde, Seguridade e Meio Ambiente até o capítulo que trata sobre o meio ambiente no texto constitucional brasileiro vigente, buscando verificar os partidos políticos mais atuantes na referida Subcomissão, além das temáticas mais debatidas na formulação do Anteprojeto, a fim concluir o foco dado pelos constituintes naquele momento histórico. Diante disso, é investigada a constitucionalização da matéria ambiental no texto constitucional uruguaio, para então comparar a (in)existência do processos de esverdeamento constitucional ocorrid os no Brasil e no Uruguai.

Em cumprimento aos rigores metodológicos, foi adotado o método de abordagem dedutivo, na medida em que a investigação parte do geral para o particular. Isto é, inicia o exame da análise do Anteprojeto da Subcomissão de Saúde, Seguridade e Meio Ambiente, bem como suas emendas, até os dispositivos dos textos constitucionais brasileiro e uruguaio que tratam sobre a matéria ambiental. Para tanto, foram analisados os seguintes documentos: Anteprojeto do Relator da Subcomissão de Saúde, Seguridade e Meio Ambiente; emendas ao Anteprojeto do relator; o 
Anteprojeto da referida subcomissão; Constituição da república Federativa do Brasil; e Constitución de La República Oriental Del Uruguay.

A natureza geral da pesquisa é qualiquantitativa, tendo em vista que, a partir da análise documental, foram contabilizados e tabulados graficamente os assuntos tratados sobre meio ambiente, os quais foram sistematizados por cada deputado constituinte e por partido à época da formação do Anteprojeto. Ademais, utilizou-se o procedimento histórico-comparativo (direito comparado) para identificar as simetrias normativas entre o texto da CF/88 e a Constitución De La República Oriental Del Uruguay de 1967, em atenção às modificações plebiscitárias posteriores ao texto constitucional uruguaio. Há predominância da técnica de investigação bibliográfica, documental e exploratória.

Em um primeiro momento, a pesquisa se preocupa em contextualizar, em linhas gerais, a formação da Assembleia Nacional Constituinte e a dinâmica adotada para a elaboração do Anteprojeto no âmbito da Subcomissão de Saúde, Seguridade e Meio Ambiente. No segundo capítulo há apresentação das informações coletadas no Anteprojeto, após processo de tabulação metodológica e sistematização gráfica do percentual de partidos políticos que realizaram propostas em matéria ambiental na referida Subcomissão, bem como demonstração quantitativa dos temas que mais aparecem nas emendas ao Anteprojeto.

No terceiro momento, a pesquisa se debruça na análise comparativa entre a Constituição Federal do Brasil de 1988 e a Constitución De La República Oriental Del Uruguay de 1967, no que se refere à matéria ambiental. Trata-se de uma análise que se justifica na necessidade de avançar nas discussões que envolvem o direito na perspectiva ecológico-ambiental, tendo como ponto de partida a norma insculpida no art. 225 da CF/88, além de estabelecer um parâmetro de análise que possa colaborar aos mais recentes estudos do (novo) constitucionalismo latinoamericano, o qual presa pela ideia do bem viver contraposta à uma lógica de desenvolvimento insustentável, economicamente, socialmente e/ou ambientalmente.

\section{CONSIDERAÇÕES SOBRE A FORMAÇ̃̃O DA ASSEMBLEIA NACIONAL CONSTITUINTE, SUA DINÂMICA DE DELIBERAÇÃO E SUA INFLUÊNCIA NO ESVERDEAMENTO DO TEXTO CONSTITUCIONAL}

A Emenda Constitucional (EC) $\mathrm{n}^{\circ}$ 26, de 27 de novembro de 1985, assinada pela mesa da Câmara dos Deputados e pela mesa do Senado Federal, ambas presididas respectivamente por Ulysses Guimarães (PMDB/SP) ${ }^{3}$ e José Fragelli (PMDB/MS $)^{4}$, teve por objetivo convocar a Assembleia Nacional Constituinte. A disposição do art. $3^{\circ}$ da referida Emenda previa que a promulgação da Constituição decorreria mediante aprovação da maioria absoluta dos membros da ANC, após discussão em dois turnos e votação.

No que tange à dinâmica dos trabalhos, definição da atividade de presidências, secretariados, das Comissões Constitucionais e de suas respectivas Subcomissões, seguiu-se as disposições da Resolução da Assembleia Nacional Constituinte no 2, de 25 de março de 1987, a qual definiu o Regimento Interno da ANC. Trata-se de uma resolução que, em caráter preambular, chama a atenção para o momento histórico de ascensão do Estado Democrático de Direito, tido no documento como um "momento decisivo da vigorosa luta do povo brasileiro pelo término do regime autoritário" e que "sepultará definitivamente a legislação antidemocrática do regime autoritário” (BRASIL, 1987).

${ }^{3}$ Ulysses Guimarães (PMDB/SP), foi um importante político e atuante Constituinte no cenário da redemocratização do Brasil e instauraçãodoEstado Democrático deDireito. Responsável pela presidência da Câmara dos Deputados à época do poder constituinte originário e foi um dos grandes opositores do regime militar. Sua morte se deu por um acidente de helicóptero e nunca se teve notícias sobre o seu corpo. ${ }^{4}$ José Fragelli (PMDB/MS) foi promotor de justiça do Estado de Mato Grosso do Sul e figurou como presidente do Senado Federal à época da Constituinte. 


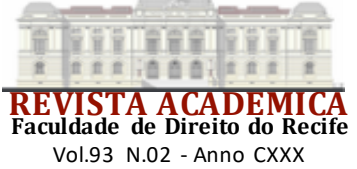

A composição da ANC contava com 487 Deputados Federais, 49 Senadores eleitos no ano de 1986 e outros 23 Senad ores ingressos em 1982 (SEROTINI, 2018). Assim, é possível dizer que o texto constitucional brasileiro em vigência não nasceu de forma simples e superficial, porque houve ampla discussão no âmbito das 8 comissões temáticas, cada uma dividida em 3 subcomissões (SEROTINI, 2018), com base na Resolução da ANC n ${ }^{\circ}$ 2/1987, contando com a participação popular, ainda que de forma inconstante e muitas vezes desforme (BRANDÃO, 2011).

Neste sentido, essa mesma resolução em seu art. 15 institui as seguintes Comissões para a elaboração do Projeto Constitucional : I - Comissão da Soberania e dos Direitos e Garantias do Homem e da Mulher; II - Comissão da Organização do Estado; III - Comissão da Organização dos Poderes e Sistema de Governo; IV - Comissão da Organização Eleitoral, Partidária e Garantia das Instituições; V - Comissão do Sistema Tributário, Orçamento e Finança; VI - Comissão da Ordem Econômica; VII - Comissão da Ordem Social; VIII - Comissão da Família, da Educação, Cultura e Esportes, da Ciência e Tecnologia e daComunicação e IX - Comissão de Sistematização (BRASIL, 1987). Esta última Comissão teve como função reunir e compatibilizar as matérias tratadas e aprovadas pelas demais comissões, adstrita aos Anteprojetos.

Importa para a presente pesquisa a Comissão da Ordem Social (VII). Isso porque para além de ser constituída pela Subcomissão dos Direitos dos Trabalhadores e Servidores Públicos e pela Subcomissão dos Negros, Populações Indígenas, Pessoas Deficientes e Minorias, trata-se da Comissão a qual a Subcomissão de Saúde, Seguridade e do Meio Ambiente, objeto de análise do presente estudo, faz parte, cuja relatoria ficou a cargo do Deputado Constituinte Carlos Mosconi (PMDB/MG). A análise tem como foco a referida Subcomissão porque é a que permite pensar como se deu o processo de esverdeamento do texto constitucional brasileiro, debate iniciado já no Anteprojeto que abordou a matéria ambiental.

O Regimento Interno da ANC colocou a cargo dos relatores realizar o relatório fundamentado e o Anteprojeto de cada Subcomissão, após deliberações, audiências públicas e apresentação de emendas pelos Deputados Constituintes. Importa mencionar que a "relatoria das subcomissões era uma das principais funções exercida por um constituinte, a ponto de parte considerável da elaboração do anteprojeto ser realizada em seus gabinetes, com seus assessores e pessoas de sua confiança" (SEROTINI, 2018, p. 9).

O estudo de Brandão (2011, p. 81) aponta aspectos interessantes sobre a participação popular na ANC, o qual mostra que entre novembro de 1986 e setembro de 1988, em um contexto de "225 eventos diferentes de ações coletivas relacionadas ao processo constituinte", constatou-se a "média mensal de 9,78 mobilizações sociais em torno da ANC no período". A partir dessa constatação, verificou-se também que:

O tipo de ação coletiva mais empregado foi as demonstrações públicas (manifestações, comícios, etc.), com 40 eventos diferentes no período (16\% do total), sendo complementado por 27 (10,8\%) Caravanas a Brasília e lobbies de maior ou menor grau nos corredores e no Plenário do Congresso Nacional (BRANDÃO, 2011, p. 84).

Ademais, o estudo realizado por Brandão (2011, p. 161) indica que, de modo geral, "o principal impacto da mobilização social na Assembleia Nacional Constituinte foi a influência que os ativistas tiveram na aprovação de alguns dos direitos sociais presentes na nova carta magna".

No que se refere à matéria ambiental, destaca-se que muito embora "as emendas populares que tiveram maior impacto foram aquelas relativas ao meio ambiente, saúde, educação, reforma urbana, direitos das crianças e adolescentes, direitos da mulher, direitos dos trabalhadores", bem como "a emenda sobre a iniciativa popular de lei" (BRANDÃO, 2011, p. 161), verifica-se que "não foi apresentada à Assembleia Nacional Constituinte nenhuma emenda popular centrada na defesa ampla do meio ambiente" (BRANDÃO, 2011, p. 175). Isso quer dizer que, apesar de ser um assunto que se sustenta como uma inovação no constitucionalismo histórico do Brasil, ainda 
há muito o que ser debatido em função do Estado de Direito Ecológico distante do antropocentrismo, do extrativismo irresponsável e de uma economia que se demonstra cada vez mais marrom e que precisa ser tendente ao esverdeamento (PERALTA, 2017).

Diante da metodologia e dos objetivos adotados no presente estudo, não se deve perder de vista a contribuição ao debate acerca do esverdeamento das normas jurídicas constitucionais. Isto é, apresentar novas contribuições que reverberam na consolidação teórica de que a proteção ao meio ambiente em função do bem comum, perfaz-se também pela técnica de esverdeamento dos direitos culturais, econômicos e sociais (MAZZUOLI; TEIXEIRA, 2013). Trata-se de uma observação necessária desde a construção da norma constitucional no âmbito das comissões originadas na ANC, porque os assuntos debatidos nessa fase podem refletir de forma significativa, em maior ou menor grau, no texto constitucional promulgado em 1988.

A tendente ecologização do direito como um todo deve se valer das mais variadas técnicas contributivas para efetivo avanço na pauta que compreende a vida em seu sentido holístico e sistêmico, de modo a questionar as práticas puramente cartesianas na relação do homem para com a natureza, vez que aquele é integrante desta (CAPRA, 2006a). Já se encontra na literatura abord agens que propõe, por exemplo, uma nova racionalidade ambiental no antropoceno mediante o esverdeamento das questões econômicas, como sendo um dos caminhos para se alcançar a sustentabilidade em um cenário de crise ecológica (PERALTA, 2017).

Conforme assevera Sarlet e Fensterseifer (2019), as mais recentes discussões que abordam valores em favor da defesa ecológica, impulsionadas a partir da década de 1970, recaem também na Teoria do Direito Constitucional e o próprio Direito Constitucional em si. É certo que a sua consolidação teórica no tempo passa pela conquista e reafirmação de valores ligados aos direitos liberais e sociais, sendo a proteção do meio ambiente ecologicamente equilibrado a principal vereda das novas acepções epistêmicas do constitucionalismo, em que se busca a proteção ambiental na senda matricial do direito constitucional. O termo "esverdear" em Pereira da Silva (2002), regozija um passo adiante no processo contínuo e dinâmico da teorização do direito constitucional ambiental ou ecológico, o que ampara a importância de entender esse processo desde o poder constituinte originário no âmbito da ANC, além de estudos comparados a outros textos constitucionais circunvizinhos geográficos.

É neste sentido que pensar a transdisciplinariedade do Direito e seu processo de ecologização ou esverdeamento, "objetiva internalizar questões ambientais no Direito para implementar a sustentabilidade através de regulação, controle e, se necessário, penalização de atividades sociais e econômicas" (POPE, 2017, p. 320), movimento que ganha força na segunda metade do século XX. Pensar o Estado de Direito Ecológico, portanto, não pode ser reduzido em uma mera retórica de vanguard a passageira, mas sim, deve ser construíd a com o amparo de análises científicas e em continuid ade às contribuições verificad as desde a Conferência das Nações Unid as para o Meio Ambiente ocorrida em Estocolmo, exercendo significativo reflexo nas constituições que se sucederam (BAHIA; LUZ, 2017).

Pensar o esverdeamento do texto constitucional, portanto, deve ser no sentido de considerá-lo como um necessário ponto de mutação no pensamento jurídico, capaz de refletir efeitos diretos nas práticas sociopolíticas correlatas ao aspecto ecológico da vida (CAPRA, 2006b). Esse movimento que Mazzuoli e Teixeira (2013) denominam como "greening”, são importantes no contexto de crise ambiental para que não haja um hiato entre as normas constitucionais de tutela ambiental e a inclinação normativa em prol do Estado de Direito Ecológico.

Diante das considerações gerais sobre a atividade da Assembleia Nacional Constituinte e elaboração do Projeto Constitucional ulteriormente promulgado em 05 de outubro de 1988, a abordagem seguinte debruça-se sobre o Anteprojeto da Subcomissão de Saúde, Seguridade e do Meio Ambiente, braço da Comissão da Ordem Social. Trata-se de explorar a fase embrionária do texto constitucional brasileiro do ponto de vista do esverdeamento da própria base de projeção do 


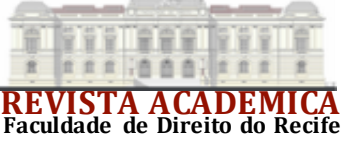

Vol.93 N.02 - Anno CXXX

texto em vigência, para compreender de forma sistemática os principais pontos relativos à matéria ambiental que o referido Anteprojeto discutiu.

Afinal, é fato que o tratamento ambiental na legislação brasileira enfrenta o seguinte dilema: "se o legislad or não regula, os conflitos se acirram; se regula, os preceitos correm o risco de não serem aplicados ou de perecerem, passivos e estupefatos, diante da reação de poderosos interesses econômicos e políticos" (BENJAMIN, 2012, p. 154). Logo, a análise sob a técnica do esverdeamento do texto normativo desde o Projeto Constitucional pretende "aquilatar a constitucionalização da proteção do meio ambiente, nela se enxergando um avanço ético-jurídico mensurável não só pela análise formal das normas, mas também pela prática constitucional" (BENJAMIN, 2012, p. 154), de forma a possibilitar também uma abordagem comparada a países circunvizinhos (como é o caso do Uruguai, abordagem melhor detalhada no Capítulo 4 do presente texto).

Refletir sobre a atuação dos Deputados Constituintes na formulação das disposições constitucionais acerca do meio ambiente e os principais temas discutidos, permite contribuir com os mais recentes estudos constitucionais e de tutela do meio ambiente ecologicamente equilibrado descrito no art. $225 \mathrm{daCF} / 88$. Avança também na compreensão fenomenológica do esverdeamento constitucional em um cenário de tendente construção do Estado de Direito Ecológico e, após, permite análises comparadas a outro Estado constitucional para verificar a realidade normativa sob a técnica ecológica ou esverdeada.

Afinal de contas, conforme assevera Capra e Mattei (2018, p. 152), vem sendo consolidada cada vez mais a ideia de que "uma visão sistêmica da natureza do direito como uma rede viva de comunidades que permitam a 'emergência' de novas formas jurídicas, a fim de manter a sobrevivência de nosso planeta, é algo que ainda está por vir”. Faz-se salutar, portanto, verificar essa tendência no âmago da rotina legislativa do poder constituinte originário brasileiro.

\section{A MATÉRIA AMBIENTAL DO ANTEPROJETO AO TEXTO CONSTITUCIONAL BRASILEIRO DE 1988 E SEU ESCOPO ESVERDEADO}

O legislador constituinte originário tratou o tema ambiental em um capítulo específico da Constituição da República Federativa do Brasil de 1988 (CF/88), considerado por Benjamin (2007, p. 86) "capítulo dos mais modernos [...]". Logra êxito, neste ínterim, a afirmação de Silva (1994, p. 717) de que o "capítulo do meio ambiente é um dos mais importantes e avançados da Constituição de 1988". Contudo, as normas de tutela do meio ambiente não ficaram restritas ao artigo 225, pois, conforme observa Barroso (1992, p. 177) "[...] são encontradas difusamente ao longo do texto constitucional".

No que se refere à elevação normativa da matéria ambiental no texto constitucional de 1988 no Brasil, Benjamin (2007, p. 86) assevera que "[...] saltou-se do estágio da miserabilidade ecológico-constitucional, própria das Constituições liberais anteriores, para um outro que, de modo adequado, pode ser apelidado de opulência ecológico constitucional”. Por estes motivos, há que se concordar com Silva (2009, p. 46) ao afirmar que a Constituição Federal de 1998 "é uma constituição eminentemente ambientalista".

Isto se deu no processo de esverdeamento dos textos constitucionais, ocorrido após a Conferência das Nações Unidas sobre o Desenvolvimento e Meio Ambiente Humano, ocorrida em Estocolmo em junho de 1972, reunindo 113 países. Tal processo, constitucionalizou o princípio do desenvolvimento sustentável, em uma nova perspectiva de uma constituição verde ou de um esverdear constitucional. Assim, sujeitou o crescimento econômico a limites socioecológicos.

Segundo os pesquisadores Mazzuoli e Teixeira (2013, p. 207), "greening" ou esverdeamento é justamente a ideia de entender a proteção ao meio ambiente pela via reflexa ou por "ricochete" nos sistemas regionais de proteção aos direitos humanos no âmbito do Direito Internacional. Uma vez que a Convenção Americana Sobre Direitos Humanos não faz menção ao 
direito ambiental, "para que questões de cunho ambiental sejam submetidas ao sistema interamericano, é preciso socorrer-se ao chamado greening ou "esverdeamento", tido pelos autores como um "fenômeno que ocorre quando se tenta (e se consegue) proteger direitos de cunho ambiental nos sistemas regionais de direitos humanos [...]” (MAZZUOLI; TEIXEIRA, 2013, p. 210).

O esverdear da $\mathrm{CF} / 88$, positivou que o desenvolvimento que atende ao interesse público, à coletividade e à sociedade, é aquele correlacionado à sustentabilidade. Ou seja, um desenvolvimento duradouro, equilibrado, homeostático, que atende às gerações atuais, sem limitar as possibilidades das gerações futuras, ainda nem mesmo gestadas (FREITAS, 2011). Este processo se deu "diante da constatação de que os recursos ambientais são a base da produção e economia mundial, mas não são inesgotáveis, como outrora se pensou [...]" (MIRANDA, 2014, p. 12). A partir disso, vários princípios internacionais foram constitucionalizados, como o do "desenvolvimento sustentável e da função social vieram a condicionar as atividades econômicas, e, portanto, a propriedade, buscando uma coexistência harmônica entre economia e meio ambiente, em um processo, aqui denominad o do esverd ear dos ordenamentos jurídicos" (MIRANDA, 2014, p. 12).

Neste sentido, para que tenham efetividade este esverdeamento, os preceitos constitucionais ambientais devem ser operados de forma a colocar o meio ambiente como fim das decisões, sejam elas, públicas ou privadas, e, não como meio. Portanto, a economia deve se amoldar às necessidades de um Estad o constitucional ecológico e de uma democracia empenhada na causa da sustentabilidade (CANOTILHO, 2011).

Essa compressão de esverdeamento constitucional e da posição do Brasil no cenário internacional, que, além de histórica, foi de vanguarda, também está presente no discurso do Deputado Ulysses Guimarães (PMDB/SP) na ocasião da promulgação da Constituição Federal. O então Presidente da Câmara dos Deputados asseverou que "é consagrador o testemunho da ONU de que nenhuma outra Carta no mundo tenha dedicado mais espaço ao meio ambiente do que a que vamos promulgar" (GUIMAR ÃES, 2008, p. 599).

Trata-se de um posicionamento que constitui um indicativo muito próximo à maneira como a matéria ambiental fora tratada no âmbito do Poder Constituinte Originário e que resultou no art. 225 do texto constitucional promulgado. A hermenêutica possível que se coloca da leitura do capítulo sobre o meio ambiente, do texto constitucional, portanto, é de que "o aspecto conservacionista e ecológico-sustentável do meio ambiente" é "um direito que não permite retrocessos" (CARVALHO; ROSA, 2020, p. 638), cabendo às "funções estatais obstar excessos na definição das escolhas sobre como é possível e como se desenvolverá a existência da humanidade" (AYALA, 2010, p. 31).

Da análise do Anteprojeto da Subcomissão de Saúde, Seguridade e Meio Ambiente e das emendas propostas por Deputados Constituintes, é possível coletar informações que agregam a discussão sobre a tutela do meio ambiente consolidada na CF/88. Para fins didáticos, a pesquisa definiu dois vetores de análise para o processo de tabulação numérica das informações: a) o percentual de emendas apresentadas ao Anteprojeto sobre a matéria ambiental categorizada por partidos políticos; e b) a ordenação percentual dos 20 temas correlatos ao meio ambiente mais discutidos nas emendas propostas pelos Deputados Constituintes ao Anteprojeto.

Antes de adentrar na análise dos dados propriamente dita, é importante ressaltar que a criação do Anteprojeto da Subcomissão de Saúde, Seguridade e Meio Ambiente contou com a atuação de Constituintes de diversos partidos. São eles: Partido Movimento Democrático Brasileiro (PMDB); Partido Trabalhista Brasileiro (PTB); Partido dos Trabalhadores (PT); Partido Liberal (PL); Partido Democrático Social (PDS); Partid o Democrático Trabalhista (PDT); Partido da Frente Liberal (PFL) ${ }^{5}$; e Partido Comunista Brasileiro (PCB). O período histórico de transição

${ }^{5}$ Atual Democratas (DEM). 
entre regimes de governo favoreceu a atividade pluripartidária na construção do Projeto Constitucional.

Durante o governo Sarney, o pluripartidarismo foi ampliado, legalizando-se partidos como PCB e o PC do B, surgindo novos como o PSDB (dissidência de membros do PMDB) e o PL (Partido Liberal), formado por ideais neoliberais do empresariado. Outro avanço foi a erradicação da "famigerada" censura à imprensa, que assolou o País durante o governo militar. O sindicalismo e grandes centrais (CUT e CGT) consolidaram-se (LENZA, 2017, p. 143).

Após tabulação sistemática das informações colhidas no Anteprojeto e suas propostas de emendas, o gráfico da Figura 1 reúne as informações percentuais de emendas apresentadas ao Anteprojeto da Subcomissão apenas quanto à matéria ambiental, separadas por cada partido político atuante.

Figura 1: Percentual de emendas apresentadas ao Anteprojeto da Subcomissão de Saúde, Seguridade e Meio Ambiente sobre a matéria ambiental categorizada por partidos políticos $(\%)$

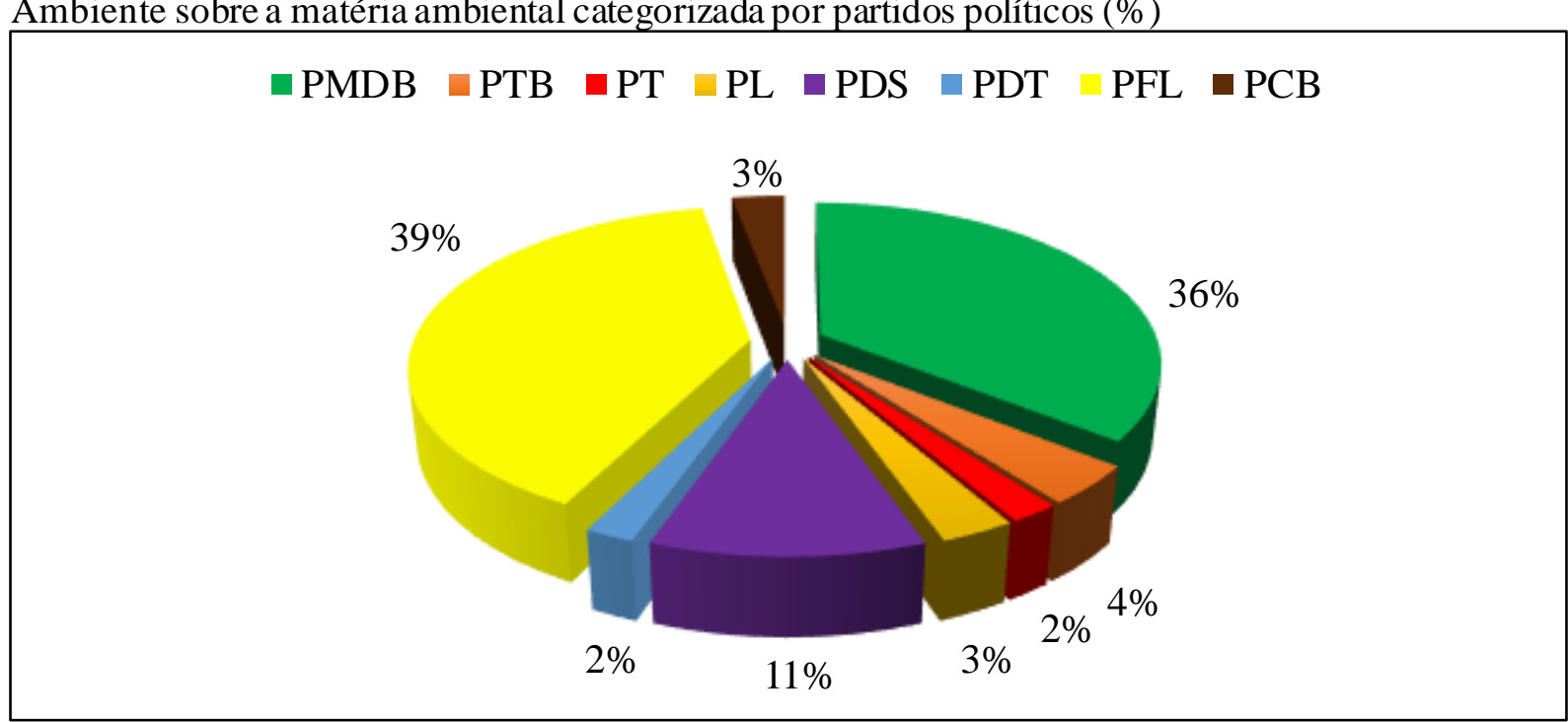

Fonte: Elaborado pelos autores mediante sistematização de informações colhidas no Anteprojeto da Subcomissão de Saúde, Seguridade e Meio Ambiente disponível no sítio eletrônico da Câmara dos Deputados (BRASIL, 1987).

Verifica-se, portanto, que os partidos políticos de maior destaque em termos quantitativos de emendas propostas ao Anteprojeto, sejam emendas supressivas ou aditivas, relacionadas ao meio ambiente foram: Partido da Frente Liberal (39\%), Partido do Movimento Democrático Brasileiro (36\%) e Partido Democrático Social (11\%).

Quanto à participação dos Deputados Constituintes, é possível constatar que os mais atuantes, na área ambiental, na Subcomissão em análise foram Antonio Carlos Mendes Thame (PFL/SP) e Inocêncio de Oliveira (PFL/PE), responsáveis, respectivamente, por 12,87\% e 11,88\% das emendas ao Anteprojeto. Curioso observar, ademais, que dentre a totalidade de 512 Deputados Constituintes que compunham a Câmara dos Deputados, o PMDB representava 54,49\% das filiações da Casa, enquanto que o PFL contava com $23,43 \%$ e o PDS apenas com $6,44 \%$ dos Constituintes.

Da análise dos temas relacionados ao meio ambiente discutidos na formulação do Anteprojeto da Subcomissão competente pelos Constituintes mediante emendas, o gráfico da Figura 2 demonstra o percentual das 20 matérias mais abordadas. 
Figura 2: Ordenação percentual dos 20 (vinte) temas correlatos à matéria ambiental mais discutidos no

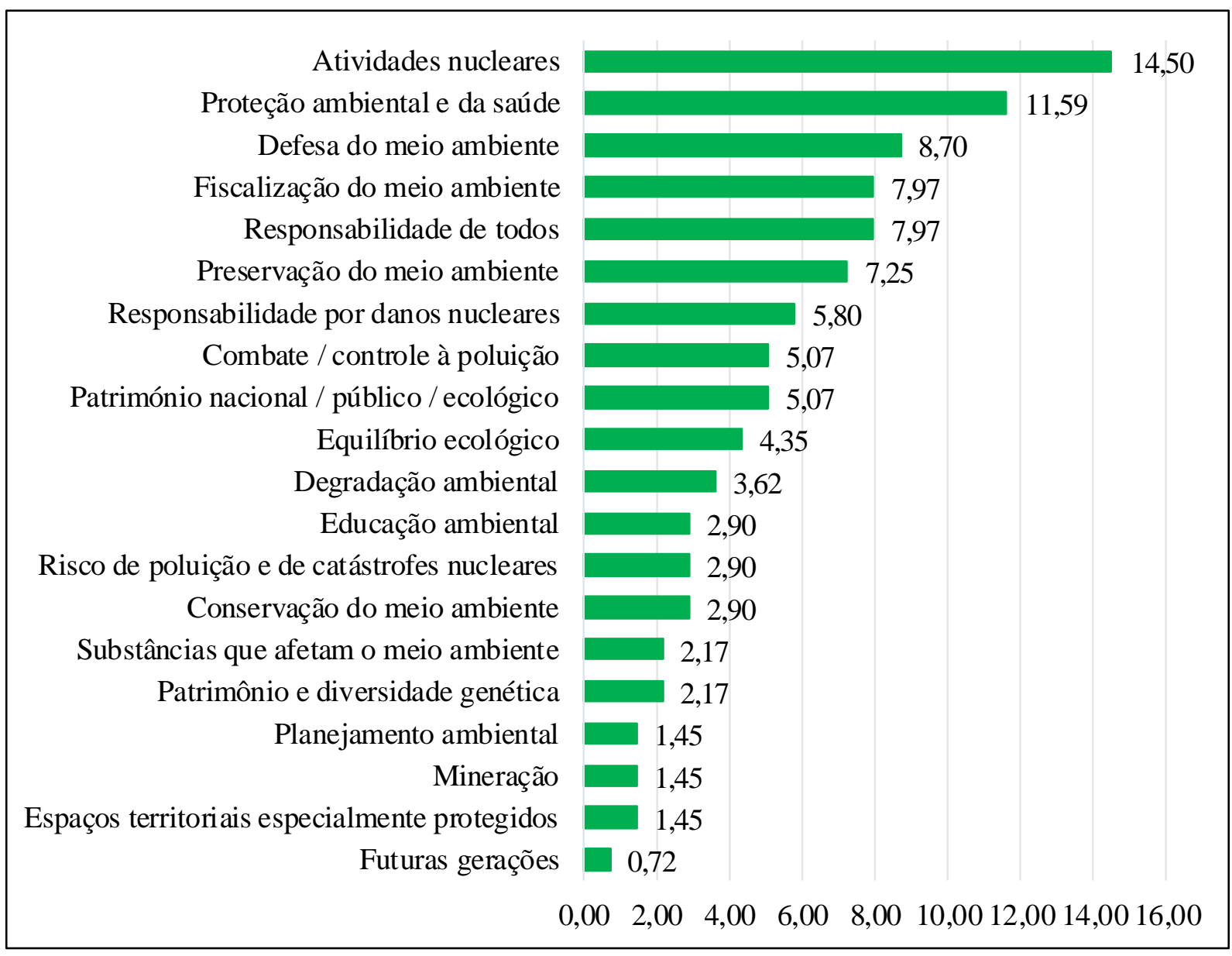

Anteprojeto da Subcomissão de Saúde, Seguridade e Meio Ambiente (\%)

Fonte: Elaborado pelos autores mediante sistematização de informações colhidas no Anteprojeto da Subcomissão de Saúde, Seguridade e Meio Ambiente disponível no sítio eletrônico da Câmara dos Deputados (BRASIL, 1987).

Percebe-se que os temas de maior destaque nas propostas de emendas ao Anteprojeto referem-se às atividades nucleares $(14,5 \%)$, proteção ambiental e da saúde $(11,59 \%)$ e defesa do meio ambiente $(8,7 \%)$. Entretanto, apesar do princípio da intergeracionalidade significar uma inovação desta carta, trazida pelo próprio caput do artigo 225, este foi o tema menos discutido, representando apenas $0,72 \%$ das emendas ao Anteprojeto. O mesmo espanto causa ao verificar que os espaços especialmente protegidos, a mineração e o patrimônio e diversidade genética, também foram objetos de poucas emendas, representando, respectivamente, 1,45\%, 1,45\% e 2,17\% delas.

Desta análise, é possível observar que os principais pontos do artigo 225 do atual texto constitucional, foram discutidos nas emendas dos parlamentares da Subcomissão da Saúde, Seguridade e Meio Ambiente, alterando significativamente o texto desde os relatórios até a promulgação da Constituição Ecológica brasileira. Desde a sua promulgação, o Capítulo destinado à matéria ambiental foi alterado uma única vez pela Emenda Constitucional no 96 de 2017, a qual acrescenta o parágrafo $7^{\circ}$ ao art. 225 , não considerando cruéis a utilização de animais em práticas desportivas cultuais, "registrad as como bem de natureza imaterial integrante do patrimônio cultural brasileiro, devendo ser regulamentadas por lei específica que assegure o bem-estar dos animais envolvidos" (BRASIL, 1988).

Ao estabelecer que "todos têm direito ao meio ambiente ecologicamente equilibrado, bem de uso comum do povo e essencial à sadia qualidade de vida, impondo-se ao Poder Público e à 


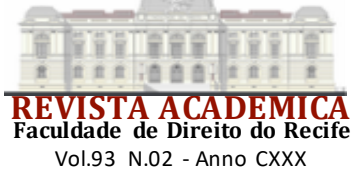

coletividade o dever de defende-lo e preservá-lo" (BRASIL, 1988) em observância ao caráter assecuratório desse desígnio às futuras gerações, percebe-se haver compatibilidade com os fundamentos de um Estado Socioambiental. Trata-se, conforme preleciona Sarlet (2018), de um reconhecimento internacional referendado pelo Relatório Nosso Futuro Comum (1987) ${ }^{6}$ na alçada da Comissão Mundial sobre o Meio Ambiente e Desenvolvimento das Nações Unidas.

O direito à proteção meio ambiente em sentido amplo, insculpido na Constituição Federal, aborda medidas e objetivos com vistas à preservação, sem deixar de lado os escopos da sustentabilidade, dever de precaução e prevenção e o princípio do poluidor pagador (SARLET, 2018). Logo, há compatibilidade com a ideia do "greening" na literatura de Mazzuoli e Teixeira (2013, p. 208), ao afirmarem que "na dimensão coletiva da proteção ambiental, o meio ambiente humano transforma-se em bem comum, resultado do esverdeamento dos direitos econômicos, sociais e culturais".

Afinal, conforme prelecionam Capra e Mattei (2018, p. 253), o direito ecocêntrico em perspectiva "requer o desenvolvimento de alguns princípios juríd icos de orientação ecológica que possam começar a traduzir a visão de mundo ecológica em teoria e prática institucionais". Da análise das matérias abordadas no Anteprojeto (Figura 2), responsável por incorporar a temática ambiental na $\mathrm{CF} / 88$ e sob a perspectiva do esverdeamento do texto constitucional, traz-se a ideia de que "os avanços ético-jurídicos nela estatuídos, ao proteger a natureza, são numerosos e inegáveis” (BENJAMIN, 2012, 155).

Ainda na concepção de Benjamin (2021, p. 155) sobre a matéria ambiental na Constituição brasileira, "chama a atenção a automização jurídica do meio ambiente, o tratamento jurídicoholístico da natureza, o reconhecimento, ao lado da dimensão intergeracional, de valor intrínseco aos outros seres vivos e ao equilíbrio ecológico", bem como "a ecologização do direito de propriedade e a instituição dos princípios da primariedade do meio ambiente e da exporabilidade limitada dos recursos naturais".

Neste sentido, com vistas a avançar nas discussões que envolvem o direito na perspectiva ecológico-ambiental na América Latina e até mesmo para o constitucionalismo andino, a próxima fase da pesquisa lança mão do direito comparado em busca de possíveis simetrias, divergências ou insurgências no trato ambiental perfilhado pela CF/88 e a Constitución de La República Oriental del Uruguay de 1967 e suas alterações plesbicitarias posteriores.

\section{A MATÉRIA AMBIENTAL COMPARADA ENTRE A CONSTITUIÇÃO FEDERAL DE 1988 E A CONSTITUCIÓN DE LA REPÚBLICA ORIENTAL DEL URUGUAY DE 1967}

A partir da tutela do meio ambiente no texto constitucional brasileiro representado pelo art. 225 e a existência de disposições correlatas à questão ambiental esparsas ao longo do texto, é possível constatar o fenômeno do esverdeamento da Constituição Federal de 1988. Trata-se de uma manifestação presente desde o próprio Anteprojeto da Subcomissão de Saúde, Seguridade e Meio Ambiente no âmago do poder constituinte originário, responsável por instaurar o Estado Democrático de Direito.

Isso é importante ser dito, porque o direito ao meio ambiente tal como se encontra na $\mathrm{CF} / 88$, uma vez constituído mediante carga de legitimidade democrática em consonância à ideia de participação pública, aponta para uma ética de solidariedade atinente à figura do próximo. Isto é, um dever intergeracional de equidade para com a vida futura em consonância aos direitos de terceira dimensão (BARBOSA, 2014).

É latente no art. 225 da Constituição Federal brasileira essa significação, na medida em que dispõe o dever de preservação ambiental às presentes gerações em solidariedade às gerações

6 "Report of the World Commission on Environment andDevelopment: Our Common Future" ou "Relatório da Comissão Mundial sobre o Meio Ambiente e Desenvolvimento: Nosso futuro comum", publicado em 1987 na Noruega, também chamado de Relatório Brundtland em homenagem à ativista política Gro Harlem Brundtland, aponta importantes medidas em função do desenvolvimento sustentável. 


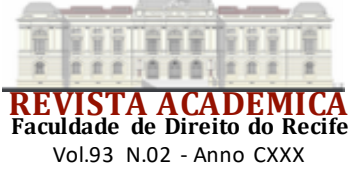

futuras. Ainda que seja um avanço, a máxima é eivada de uma concepção antropocêntrica, típica da vanguarda neoconstitucionalista de raiz eurocêntrica da época.

Antes de aplicar o métod o comparado entre a Constituição Federal de 1988 e a Constitución de la República Oriental del Uruguay de $1967^{7}$ especificamente quanto à matéria ambiental, é preciso ressalvar algumas considerações acerca da organização de ambos os Estados constitucionais.

Ao passo que o Brasil possui forma de Estado federado bicameral, governo republicano, sistema presidencialista e de regime de governo democrático, o Uruguai possui "governo republicano democrático, com o modelo semi-representativo, em que representação política e participação direta se complementam" (SANSON, 2011, p. 22), cuja forma do Estado é unitário e curiosamente bicameral, com reduzida fragmentação partidária (OLIVEIRA, 2006). O regime de governo também é democrático e representativo, porém, com a administração do Estado mais centralizada que o Brasil, o que faz sentido ante as diferenças sociais e geográficas.

A Constituição Federal de 1988 é rígida, isto é, sua alteração só pode ocorrer mediante Proposta de Emenda à Constituição (PEC), votada em dois turnos, nas duas Casas do Congresso Nacional e desde que obtenha 3/5 dos votos de seus membros. Embora seja de difícil alteração ante o caráter rígido, é muito comum que o poder constituinte derivad o se expresse mediante PEC, sendo os legitimados para proposição o Presidente da República, mais da metade de todas as Assembleias Legislativas das unidades da Federação (ALs) e no mínimo 1/3 dos membros da Câmara dos Deputados ou do Senado Federal (BRASIL, 1988) ${ }^{8}$.

Na Constituição da República Oriental do Uruguai, entretanto, de acordo com a pesquisa de Oliveira (2006, p. 308), "os referend os são utilizad os com frequência”, os quais podem ocorrer: a) por iniciativa popular de $10 \%$ dos cidadãos inscritos no Registro Cívico Nacional, podendo ambas as Câmaras formularem projetos substitutivos a ser submetido para decisão plesbicitaria, juntamente com a iniciativa popular; b) por projeto de reforma formulado por $2 / 5$ dos membros da Assembleia Geral e que será submetido ao plesbicito na primeira eleição que se realize ${ }^{9}$; e c) por projetos de Senadores, Representantes e o Poder Executivo, desde que aprovados por maioria absoluta do total de componentes da Assembleia Geral (URUGUAY, 1967).

Neste sentido, a Constituição uruguaia, desde o seu advento em 1967, passou por quatro alterações plesbicitarias: 26 de novembro de 1989; 26 de novembro de 1994; 8 de dezembro de 1996; e 31 de outubro de 2004. Interessa para a presente pesquisa esta última, por se tratar daúnica disposição constitucional que está relacionado à matéria ambiental. Afinal, diferentemente da Constituição Federal de 1988 e sem adentrar em especificidades históricas do povo uruguaio por não constituir o objetivo deste estudo, a Constitución de la República não possui um capítulo próprio destinado a elevar o direito ambiental ao patamar constitucional. Sequer há disposições voltadas para um meio ambiente ecologicamente equilibrado, definição de unidades de conservação ou mesmo diretrizes voltadas para o desenvolvimento sustentável em sentido amplo.

O art. 47 da Constitución de la República Oriental del Uruguay de 1967, dispõe no caput, de maneira comedida e sem maiores especificidades, o seguinte comando relacionado à matéria ambiental: "La protección del medio ambiente es de interés general. Las personas deberán abstenerse de cualquier acto que cause depredación o contaminación graves al médio ambiente.

${ }^{7}$ Constituição da República Oriental do Uruguai de 1967.

${ }^{8}$ Importante lembrar que a $\mathrm{CF} / 88$, no art. $60, \S 4^{\circ}$, elenca o quenão pode ser alterado mediante umaEmenda Constitucional, comumente conhecido como "cláusulas pétreas". São elas: I - a forma federativa de Estado; II - o voto direto, secreto, universal e periódico; III - a separação dos Poderes; e IV - os direitos e garantias individuais (BRASIL, 1988).

${ }^{9}$ Neste caso, a norma constitucional Uruguai prevê também o procedimento, dispondo que "Para que el plebiscito sea afirmativo en los casos de los incisos A) y B), se requerirá que vote por "SI" la mayoría absoluta de los ciudadanos que concurran a los comicios, la que debe representar por lo menos, el treinta y cinco por ciento del total de inscriptos en el Registro Cívico Nacional" (URUGUAY, 1967). 


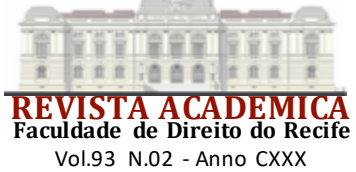

La ley regulamentará esta disposición y podrá prever sanciones para los transgresores" $\left(\right.$ URUGUAY, 1967) ${ }^{10}$. Apesar de ser o único artigo voltado para a tutela ambiental, constata-se uma peculiaridade que inova o constitucionalismo uruguaio na história e o latino-americano por servir de exemplo a outros Estados constitucionais.

O grande diferencial da Constituição uruguaia, que faz dela uma referência mundial acerca do constitucionalismo latino-americano e que sobreveio com o advento da modificação plesbicitaria de 31 de outubro de 2004. Através da qual reconheceu a água e o saneamento básico como direito humano e fundamental. Constata-se, oportunamente, na literatura de Arrojo (2006, p. 93) "en el 2004, el pueblo Uruguayo en referéndum y com el $64 \%$ de los votos emitidos, decidía incorporar a la Constitución el reconocimiento del agua potable como un derecho humano". ${ }^{11}$

O estudo de Burckhart e Melo (2019, p. 407-408) complementa que "a iniciativa desse referendo foi realizada pela Comisión Nacional de Defensa del Agua y de la Vida (CNDAV), criada em 2002 como contraponto às determinações do Fundo Monetário Internacional e do governo uruguaio", tendo em vista a ameaça de "privatização de água e saneamento em todo o país" (BURCKHART; MELO, 2019, p. 407-408). Em decorrência desse acontecimento histórico e de ressignificação do tratamento normativo da água e saneamento básico, Burckhart e Melo (2019, p. 408) destacam:

O processode mobilizaçãopolíticalevou o Uruguai a ser o primeiro país do globo a reconhecer o direito humanoe fundamentalà água e ao saneamentoem um texto constitucional e de determinar a participação cidadã na gestão e controle das fontes de água. Além desse reconhecimento jurídico simbólico, o texto constitucional ainda determina a criação de uma política nacional de águas que deve ser baseada no ordenamento do território, na gestão sustentável com participação cidadão e na prevalência dos interesses sociais em detrimento dos econômicos (art. 47, 1, "a", "b", "c"e "d").

No sentido de garantir a prevalência dos interesses sociais, para além da gestão participativa dos recursos hídricos e serviços de saneamento, o estudo de Carvalho, Rosa e Miranda (2020, p. 19) chama a atenção para o fato do legislador constituinte derivado da vontade popular no Uruguai determinar a perda de efeitos as autorizações, permissões e concessões de serviços hídricos que violem, de alguma maneira, as disposições constitucionais incluídas pelo próprio referendo plebiscitário. Assim, os pesquisadores apontam que o texto constitucional uruguaio "foi além e conferiu natureza transindividual, especificamente difusa, ao subordinar a água ao interesse geral, além de ter considerado a água um macrobem, unitário e indivisível”.

Outra observação importante de Carvalho, Rosa e Miranda (2020), diz respeito à aplicação do princípio da solidariedade como reafirmação dos direitos de terceira dimensão no constitucionalismo latino-americano, encarrilhado pelo Uruguai. Isso porque, conforme argumentam os autores, o texto constitucional uruguaio prevê o abastecimento de água a outro país quando este estiver em escassez, mediante aprovação de $3 / 5$ do total de membros da Câmara, sendo a justificativa dessa disposição justamente os ditames da solidariedade. Portanto, no texto constitucional uruguaio, bem como no brasileiro, não há, desprendimento da concepção antropocêntrica, porque a vida humana no compartilhamento da água é colocada no centro do debate, e não a vida da totalidade ecologicamente considerada.

${ }^{10}$ A proteção do meio ambiente é do interesse geral. As pessoas devem se abster de qualquer ato que cause depredação ou contaminação grave ao meio ambiente. A lei irá regulamentar esta disposição e poderá prever sanções para os transgressores (tradução nossa).

${ }^{11}$ Em 2004, o povo uruguaio, em referendo e com 64\% dos votos emitidos, decidiu incorporar à Constituição o reconhecimento da água potável como direito humano (tradução nossa). 


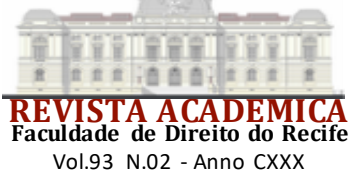

A carga normativa da água e saneamento como um direito humano e fundamental, ao menos no aspecto formal, não é expressamente reconhecido pela Constituição Federal do Brasil de 1988. Porém, "trata-se de uma hermenêutica possível através da união entre a cláusula de abertura constitucional, do art. $5^{\circ}, \S 2^{\circ}$, e do direito ao meio ambiente ecologicamente equilibrado, previsto no art. 225, ambos da CF/88" (CARVALHO; ROSA; MIRANDA, 2020, p. 34). Além disso, "existe um movimento no âmbito da atividade legislativa do Congresso Nacional que pretende incluir expressamente no texto constitucional, a água potável enquanto direito fundamentalmente humano" (CARVALHO; ROSA; MIRANDA, 2020, p. 34). Neste sentido, os referidos autores constataram na pesquisa a existência de três Propostas de Emendas Constitucionais no âmbito do Congresso Nacional do Brasil, que visam incluir os recursos hídricos no rol de direitos humanos e fundamentais na Constituição Federal de 1988. São elas: PEC n 258/2016 na Câmara dos Deputados; PEC nº 04/2018 no Senado Federal; e a PEC no 430/2018 também na Câmara dos Deputados (CARVALHO; ROSA; MIRANDA, 2020).

Veja-se, portanto, de acord o com o gráfico da Figura 2, que a questão da água e saneamento não foi debatida de forma específica e pormenorizada no âmbito do Anteprojeto da Subcomissão da Saúde, Seguridade e Meio Ambiente na fase embrionária da CF/88. Entretanto, a tutela ambiental contida no texto constitucional promulgado em 1988, em seu Art. 23, prevê a competência material comum entre União, Estados, Distrito federal e Municípios na visão de, assim, estabelece aos entes da federação a cooperação solidária no trato da matéria ambiental, já que a gestão das problemáticas ambientais "não pode ser veiculada de forma solitária e independente" (AYALA, 2010, p. 13). Isso deve ser estendido inclusive aos direitos acobertados pela cláusula de abertura constitucional, principalmente na afirmação da água enquanto um direito humano e fundamental.

Logra êxito, ademais, a afirmação de Sanson (2011, p. 27) no sentido de que "a República Oriental do Uruguai é um dos países de maior tradição democrática na América Latina, promovendo em seu reduzido território grandes avanços sociais e institucionais antes mesmo de outras nações continentais". Na perspectiva teórica o fenômeno de constitucionalização da água enquanto um direito humano e fundamental na Constituição do Uruguai, "projeta como uma tendência jurídica de abertura cognitiva do próprio constitucionalismo democrático contemporâneo, da mesma forma que a proteção constitucional do meio ambiente em lato sensu também o é" (BURCKHART; MELO, 2019, p. 414).

\section{CONCLUSÃO}

O esverdeamento dos direitos sociais, culturais e econômicos é uma realidade legislativa nos Estados constitucionais do sul e do norte global, mas a efetivação destes direitos, nem sempre, ocorrem a contento, o que deve ser assunto para uma outra pesquisa. A compreensão de desenvolvimento sustentável e de preservação do meio ambiente passa pela necessária aproximação ao ecocentrismo, a qual, na maioria das vezes cede às pautas neoliberais, que internaliza a sustentabilidade e a transforma em mercadoria. Contudo a Constitucionalização desses direitos, esverdeando os ordenamentos jurídicos de diversos países ocidentais, como o Brasil e o Uruguai, que são objeto desta pesquisa, é louvável e merecedor de nota.

No caso da Constituição Federal de 1988, esse processo de esverdeamento esteve presente desde a sua fase gênese no âmbito da Subcomissão de Saúde, Seguridade e Meio Ambiente, o que privilegiou a existência de um capítulo destinado exclusivamente à tutela ambiental após longas discussões para a formulação do Projeto de Constituição. Trata-se de importante passo na consolidação de um Estado de Direito Ecológico ainda em construção, cujo início se deu na fase de construção do Projeto do que hoje vem sendo denominado de Constituição Ecológica.

Aliado ao processo de redemocratização do Brasil e institucionalização do Estado Democrático de Direito, ainda que sobre a influência antropocêntrica do neoconstitucionalismo 
europeu, o direito ambiental encartado na $\mathrm{CF} / 88$ foi levado a sério no átimo de sua projeção no Anteprojeto constituinte. Contou-se com a participação pluripartidária ativa de Deputados Constituintes mediante emendas aditivas ou supressivas, com destaque do Partido da Frente Liberal (atual Democratas), Partido Movimento Democrático Brasileiro e Partido Democrático Social. É fato que a participação direta de movimentos sociais exerceu maior influência na formação dos direitos sociais da $\mathrm{CF} / 88$, mas os impactos foram significativos na formação das disposições ambientais, embora não tenha sido apresentada à Assembleia Nacional Constituinte nenhuma emenda comum de iniciativa popular que contribuísse com a defesa do meio ambiente de forma extensiva.

A partir do recorte gráfico quantitativo apresentado na Figura 2 sobre os 20 temas mais discutidos no processo de constitucionalização do meio ambiente nucleado nas emendas do Anteprojeto, aquilo que mais foi levado em consideração pelos Deputados Constituintes representa exatamente a preocupação e os anseios da época, em um contexto de Guerra Fria e ameaça constante de uma guerra nuclear.

É certo que as mais recentes pesquisas que teorizam a construção do Estado de Direito Ecológico, está propenso a compreender a vida em sua totalidade sistêmica e interdependente, distante de práticas essencialmente antropocêntricas. Assim, respalda-se a hipótese de que o advento de uma eventual nova constituinte no cenário atual, as temáticas de grande relevância socioambientais dificilmente seriam a respeito de atividades nucleares, mas sim, a proteção ambiental e da saúde, mudanças climática, equilíbrio ecológico e degradação ambiental. Isso não quer dizer que a atividade nuclear seja um assunto prescindível, mas a latente e necessária ecologização do direito traria para o centro do debate discussões outras que também afetam diretamente o meio ambiente ecologicamente considerado e significaria, além disso, uma intensificação da coloração esverdeada do direito constitucional brasileiro.

Da análise comparada das disposições correspondentes ao meio ambiente no art. 225 da CF/88 e na Constitución de La República Oriental Del Uruguay de 1967, verifica-se que ambas tratam da matéria ambiental. A primeira com mais abordagens temáticas e de maior complexidade dispositiva, e a segund a de maneira sutil e condensada, que futuramente int egrou novas disposições normativas com o advento do referendo plebiscitário de 31 de outubro de 2004. Conforme trabalhado no texto, muito embora a tutela ambiental da Constituição do Uruguai não tenha uma abordagem tão expansiva quanto a Constituição brasileira de 1988, ela é a primeira carta constitucional a atribuir, de forma expressa, carga normativa à água e saneamento como um direito humano e fund amental.

Além de se tornar referência mundial sobre o trato da água no prospecto constitucional, a Constituição uruguaia serviu de inspiração para outras constituições latino-americanas, como Equad or (2008) e Bolívia (2009), inclusive Projetos de Emendas Constitucionais no Brasil, com vistas a garantir esse direito na acepção fundamentalmente humana. Assim, diante dos diferentes focos e diretrizes ambientais existentes entre a Constituição da República Federativa do Brasil de 1988 e a Constitución de La República Oriental Del Uruguay de 1967, inclusive com suas alterações plesbicitarias, pode-se dizer que se a primeira é verde, como as florestas brasileiras, e a segunda tem a tonalidade da água, predominantemente azulada ou "bluish", para fins de tutela no âmbito interamericano.

\section{REFERÊNCIAS}

ARROJO, Pedro. El reto ético de la nueva cultura del agua, funciones, valores y derechos en juego. Barcelona: Paidós Ibérica, 2006. 
AYALA, Patryck de Araujo. Direito fundamental ao ambiente, mínimo existencial ecológico e proibição de retrocesso na ordem constitucional brasileira. Revista dos Tribunais, v. 88, n. 901, p. 29-64, 2010.

BAHIA, Carolina Medeiros; LUZ, Matheus Bernadino da. Importância da participação dos grupos vulneráveis e das minorias para a promoção do Estad o de Direito Ecológico. In:

DINNEBIER, Flávia França; MORATO, José Rubens. Estado de Direito Ecológico: conceito, conteúdo e novas dimensões para a proteção da natureza. São Paulo: Inst. O direito por um Planeta Verde, 2017. E-book. Disponível em: http://www.ccj.ufpb.br/sda/contents/documentos/ebook-estado-de-direito-ecologico-prof-dr-jose-rubens-morato-leite.pdf. Acesso em: 01 nov. 2020

BARBOSA, Gleidson de Oliveira Grisoste. O dever fundamental de proteção do meio ambiente e o direito correlato: uma relação fundamental. Revista do Instituto de Direito BrasileiroRIDB da Faculdade de Direito da Universidade de Lisboa, v. 3, p. 7527-7587, 2014.

BARROSO, Luís Roberto. A proteção do meio ambiente na Constituição brasileira. Revista Forense, v. 317, n. 161, p. 167-168, 1992.

BENJAMIN, Antônio Herman. Direito constitucional ambiental brasileiro. In: CANOTILHO, José Joaquim Gomes; LEITE, José Rubéns Morato (org.). Direito constitucional ambiental brasileiro. São Paulo: Saraiva, 2007.

BENJAMIN, Antônio Herman. Direito Constitucional Ambiental Brasileiro. In: CANOTILHO, José Joaquim Gomes; LEITE, José Rubens Morato (org.). Direito Constitucional Ambiental Brasileiro. 5. ed. rev. São Paulo: Saraiva, 2012. Parte 2.

BRANDÃO, Lucas Coelho. Os movimentos sociais e a Assembleia Nacional Constituinte de 1987-1988: entre a política institucional e a participação popular. 2011. Dissertação (Mestrado em Sociologia) - Universidade de São Paulo, São Paulo, 2011.

BRASIL. Assembleia Nacional Constituinte. Comissão da Ordem Social. Subcomissão da Saúde, Seguridade e Meio Ambiente. Anteprojeto do Relator. Brasília, DF: Assembleia Nacional Constituinte, 1987. v. 192.Disponível em:

https://www.camara.leg.br/internet/constituicao20anos/DocumentosAvulsos/vol-192.pdf. Acesso em: 11 mar. 2021.

BRASIL. Assembleia Nacional Constituinte. Comissão da Ordem Social. Subcomissão da Saúde, Seguridade e Meio Ambiente. Apresentação de Emendas ao Anteprojeto do Relator. Brasília, DF: Assembleia Nacional Constituinte, 1987. v. 193.Disponível em: https://www2.camara.leg.br/atividadelegislativa/legislacao/Constituicoes_Brasileiras/constituicao-cidada/o-processoconstituinte/comissoes-e-subcomissoes/comissao7/subcomissao7b. Acesso em: 11 mar. 2021.

BRASIL. Assembleia Nacional Constituinte. Comissão da Ordem Social. Subcomissão da Saúde, Seguridade e Meio Ambiente. Anteprojeto. Brasília, DF: Assembleia Nacional Constituinte, 1987. v. 194. Disponível em:

https://www.camara.leg.br/internet/constituicao20anos/DocumentosAvulsos/vol-194.pdf. Acesso em: 11 mar. 2021. 
BRASIL. Assembleia Nacional Constituinte. Comissão da Ordem Social. Subcomissão da Saúde, Seguridade e Meio Ambiente. Anteprojeto. Brasília, DF: Assembleia Nacional Constituinte, 1987. v. 195. Disponível em:

https://www.camara.leg.br/internet/constituicao20anos/DocumentosAvulsos/vol-195.pdf. Acesso em: 11 mar. 2021.

BRASIL. Constituição (1988). Constituição da República Federativa do Brasil de 1988. Brasília, DF: Presidência da República, 1988. Disponível em: http://www.planalto.gov.br/ccivil_03/constituicao/constituicaocompilado.htm. Acesso em: 11 mar. 2021.

BRASIL. Emenda Constitucional no 26, de 27 de novembro de 1985. Convoca Assembléia Nacional Constituinte e dá outras providências. Brasília, DF: Congresso Nacional, 1985. Disponível em: http://www.planalto.gov.br/ccivil_03/constituicao/Emendas/Emc_anterior1988/emc26-85.htm. Acesso em: 11 mar. 2021.

BURCKHART, Thiago Rafael; MELO, Milena Petters. O direito à água nas Constituições da América do Sul: elementos comuns e traços distintivos. Revista Brasileira de Políticas Públicas, Brasília, v. 9, n. 2, p. 402-418, 2019. Disponível em: https://www.rel.uniceub.br/RBPP/article/view/6057. Acesso em: 11 mar. 2021.

CANOTILHO, José Joaquim Gomes. Direito constitucional ambiental português e da União Europeia. In: CANOTILHO, José Joaquim Gomes; LEITE, José Rubens Morato (org.). Direito constitucional ambiental brasileiro. 4. ed. São Paulo: Saraiva, 2011.

CAPRA, Fritjof. A teia da vida: uma nova compreensão científica dos sistemas vivos. Tradução Newton Roberval Eichemberg. São Paulo: Cultrix, 2006a.

CAPRA, Fritjof. O Ponto de Mutação. Tradução Álvaro Cabral. São Paulo: Cultrix, 2006b.

CAPRA, Fritjof; MATTEI, Ugo. A Revolução Ecojurídica: o direito sistêmico em sintonia com a natureza e a comunidade. Tradução Jeferson Luiz Camargo. São Paulo: Cultrix, 2018

CARVALHO, Luiz Guilherme; ROSA, Rosana Gomes da. Análise da constitucionalidade da gestão privada de unidades de conservação de proteção integral. Revista FIDES, v. 11, n. 2, p. 633-653, 2020.

CARVALHO, Luiz Guilherme; ROSA, Rosana Gomes da; MIRANDA, João Paulo Rocha de. O Novo Constitucionalismo Latino-americano e a Constitucionalização da Água Enquanto um Direito Humano Fundamental: os Estados-constitucionais do Brasil, Uruguai, Equador e Bolívia em foco. In: MARCONATTO, Alessandra; XAVIER, Alexandre Vicentine; MIRANDA, João Paulo Rocha de (Orgs.). Direitos Fundamentais: Análise da Fronteira da Paz até a Amazônia. Santana do Livramento: Projeto Pensar Direito - UNIPAMPA, 2020. E-book. Disponível em: https://drive.google.com/file/d/1FU_JRrbtyoYuDYWfvRB0AKBaqC6Sea2/view?fbclid=IwAR2BCKaSlbYXW7HPyisQjwGKHrKiew8a5cRYRx7dh2I9Jh19WbFTivKA7M. Acesso em: 15 fev. 2021.

FREITAS, Juarez. Sustentabilidade: direito ao futuro. 1. ed. Belo Horizonte: Fórum, 2011. 
GUIMARÃES, Ulysses. Discurso do deputado Ulysses Guimarães, presidente da Assembleia Nacional Constituinte, em 05 de outubro de 1988, por ocasião da promulgação da Constituição Federal. Revista Direito GV, v. 4, n. 2, p. 595-601, 2008.

LENZA, Pedro. Direito constitucional esquematizado. 21. ed. São Paulo: Saraiva, 2017.

MAZZUOLI, Valerio de Oliveira; TEIXEIRA, Gustavo de Faria Moreira. O direito internacional do meio ambiente e o greening da convenção americana sobre direitos humanos. Revista Direito GV.n. 9, p. 199-242, 2013.

MIRANDA, João Paulo Rocha de. A biodiversidade brasileira: aspectos jurídicos e socioambientais da sua apropriação. Barra do Garças: Pensar Direito: UFMT/CUA. Disponível em: https://drive.google.com/file/d/1eukE-

Tn4Vg84WSuCpVbnwoxsAFPvaqmX/view?fbclid=IwAR0KwmHlphk7m9S6bBjmOrxjXe5T4g-4AEZGGyBOGhyrHB5e3vpKY4_BUw. Acesso em: 12 nov. 2020.

OLIVEIRA, Luzia Helena Herrmann de. Presidencialismos em perspectiva comparada: Argentina, Brasil e Uruguai. Dados, v. 49, n. 2, p. 301-343, 2006.

PERALTA, Carlos Eduardo. Desafios para Construir uma Nova Racionalidade Ambiental no Antropoceno: o esverdeamento da economia como caminho para incentivar a sustentabilidade. In: DINNEBIER, Flávia França; MORATO, José Rubens. Estado de Direito Ecológico: conceito, conteúdo e novas dimensões para a proteção da natureza. São Paulo: Inst. O direito por um Planeta Verde, 2017. E-book. Disponível em:

http://www.ccj.ufpb.br/sda/contents/d ocumentos/e-book-estado-de-direito-ecologico-prof-drjose-rubens-morato-leite.pdf. Acesso em: 01 nov. 2020.

PEREIRA DA SILVA, Vasco. Verde cor de direito: lições do direito do ambiente. Coimbra: Almedina, 2002.

POPE, Kamila. Estado de Direito Ecológico: a ecologização do direito pelo ideal de sustentabilidade. In: DINNEBIER, Flávia França; MORATO, José Rubens. Estado de Direito Ecológico: conceito, conteúdo e novas dimensões para a proteção da natureza. São Paulo: Inst. O direito por um Planeta Verde, 2017. E-book. Disponível em:

http://www.ccj.ufpb.br/sda/contents/d ocumentos/e-book-estado-de-direito-ecologico-prof-drjose-rubens-morato-leite.pdf. Acesso em: 01 nov. 2020.

SANSON, Alexandre. Análise das estruturas institucionais democráticas da República Oriental do Uruguai pós-regime ditatorial. Cadernos de Pós-Graduação em Direito: estudo e documentos de trabalho. Tendências e Desafios do Constitucionalismo Latino-Americano. São Paulo, Comissão de Pós-Graduação da Faculd ade de Direito da USP, v. 1005, n. 3, p. 16-30, 2011 .

SARLET, Ingo Wolfgang. O conceito de Direitos Fundamentais no sistema constitucional brasileiro. In: SARLET, Ingo Wolfgang; MARINONI, Luiz Guilherme; MITIDIERO, Daniel. Curso de Direito Constitucional. 8. ed. São Paulo: Saraiva, 2018.

SARLET, Ingo Wolfgang; FENSTERSEIFER, Tiago. Direito constitucional ecológico. Constituição, Direitos Fundamentais e Proteção da Natureza. 6. ed. São Paulo: Revista dos Tribunais, 2019. 


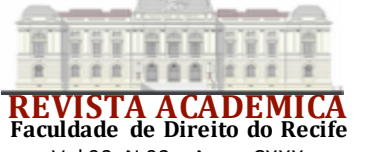

Vol.93 N.02 - Anno CXXX

SEROTINI, André. Revisitando a Constituinte de 1987/88: a tutela do meio ambiente no Brasil. Revista de Constitucionalização do Direito Brasileiro-RECONTO, v. 1, n. 1, p. 1-19, 2018.

SILVA, José Afonso da. Curso de direito constitucional positivo. 9. ed. São Paulo: Malheiros, 1994.

SILVA, José Afonso da. Direito ambiental constitucional. 7. ed. São Paulo: Malheiros, 2009.

URUGUAY. [Constitución (1967)]. Constitución de la República Oriental del Uruguay:

Constitución 1967 con las modificaciones plebiscitadas el 26 de noviembre de 1989, el 26 de noviembre de 1994, el 8 de diciembre de 1996 y el 31 de octubre de 2004. Montevideo, Uruguay: Poder Legislativo, [2004]. Disponible en:

https://parlamento.gub.uy/documentosyleyes/constitucion. Acceso en: 11 mar. 2021. 